\section{P30 SUSTAINABLE IMPLEMENTATION OF ADVANCE CARE PLANNING IN A GENERAL MEDICAL UNIT}

A Lam*, J Tan, R Ng. Tan Tock Seng Hospital, Singapore, Singapore

\subsection{6/spcare-2019-ACPICONGRESSABS. 115}

Background Singapore has a growing ageing population with an increase in chronic progressive illnesses. The need for advance care planning (ACP) has become increasingly important. It has been found that ACP is better accepted by the patient when offered by their doctor. Unfortunately, many institutions have struggled to get the main stakeholders involved.

Our aim was to integrate ACP into daily clinical practice- a systematic and sustainable model for ACP implementation in a general medical unit in an acute hospital, targetting the population who would most benefit from it.

Methods Implementation involved a three-pronged approach of promoting awareness, facilitator training and formal screening, using triggers- age $>75$ years, poor premorbid function and more than 3 recurrent admissions in a year. These triggers apply to our target group, and their simplicity makes it easy for clinicians to remember and implement. Reminders were relayed via email to the teams involved in the care of the patients, to initiate ACP discussions.

Results The implementation of ACP in the medical unit, occurred in phases.

From 2013-2014, the number of ACP discussions doubled with promotion of ACP and facilitator training.

From 2015-2016, the numbers increased by $60 \%$ after introduction of formal screening for new admissions using our three key triggers.

In 2017, these numbers were maintained even after we stopped formal screening and email reminders.

Conclusion ACP rates increased, using the three-pronged approach of implementation, with improved sustainability and consistency.

Future initiatives may focus on refining the triggers, and incorporating them into medical records systems.

\section{P31 CURRENT STATUS, NEEDS AND BARRIERS TOWARDS ADVANCE CARE PLANNING (ACP) IN NURSING HOMES}

${ }^{1}$ T Henking*, 'L Best, ' ${ }^{1}$ E Heizmann, ${ }^{2}$ B Oorschot van, ${ }^{1}$ S Neuderth*. ' University for Applied Sciences Würzburg-Schweinfurt, Würzburg, Germany; ${ }^{2}$ University Hospital Würzburg, Würzburg, Germany

\subsection{6/spcare-2019-ACPICONGRESSABS.116}

Background and objectives Fostered by a legislative initiative in 2015, German nursing homes face the challenge to implement ACP- structures. Project background is to conceptualize and evaluate a practicable ACP-concept for the region Würzburg (130.000 inhabitants, Bavaria) with 12 nursing homes. In advance of a concept development, the current status of advance care practices in nursing homes, requirements of nursing homes and possible barriers were assessed.

Methods Written survey addressed to directors of 12 nursing homes in Würzburg. The questionnaire focusses - amongst others - on structural data (number of nursing places, nursing level of residents, qualifications of staff members ...), regional networking (cooperation with general practitioners, hospitals, hospices ...), reasons for and extend of hospital admissions and reanimations, dealing with cardiac arrest, kind and amount of documentation of residents will related to end of life care, professions with function in ACP, possible barriers towards ACP and need for further support in implementing ACP.

Results $\mathrm{NH}$ are still not prepared for implementing an ACPConcept. Development of structures and support are as necessary as development of human resources and establishment of cross-provider networks. Misperceptions about legal requirements, uncertainties in communication and little time are some further barriers that have to be addressed in an ACPconcept.

Conclusion The sustainable implementation of a viable ACPconcept assumes the development of structural and personal resources and has to address popular misperceptions and communicative barriers.

\section{P32 AN EXAMINATION OF ACP IMPLEMENTATION IN AN ACUTE HOSPITAL - TOO LITTLE, TOO LATE?}

E Chua*. Tan Tock Seng Hospital, Singapore, Singapore

\subsection{6/spcare-2019-ACPICONGRESSABS.117}

ACP has been part of holistic care in Singapore since 2011. When patients do not have an ACP, healthcare teams often rely on surrogate decision-makers to determine patient's values and preferences. Several studies have been done and demonstrated a discordance of $26-35 \%$ between patients and their surrogates in decisions on CPR and extension of life. There are no national statistics on the number of ACPs that are done by surrogates. There are few studies to demonstrate the concordance of ACP at the end-of-life.

A retrospective analysis was done for patients admitted to General Medicine Department in Tan Tock Seng Hospital in 2015, who had an ACP on admission. The aim was to determine how many ACPs involved patients, secondary aims were assessment of ACP concordance at the end-of-life care.

Our study involved 56 patients, $16.07 \%$ of the ACPs involved the patient. ACP discordance was highest in those who had chosen home as the preferred place of death (PPOD), with 69.23\% passing away in the acute hospital instead of at home. $82.6 \%$ died within 1 year of the ACP and $39.47 \%$ died during the hospitalization when the ACP was first done.

ACP requires involvement of the patient to ensure an accurate reflection of their values and preferences. The biggest discordance in the ACP is in the PPOD. There are many factors that cause PPOD discordance. More training and support is needed in nursing homes and home medical services to allow patients to pass away peacefully in a place of their choice.

\section{P33 'TO TALK ABOUT IT, THAT'S A PROBLEM ...'. ANALYSIS OF NEEDS CONCERNING ADVANCE PLANNING WITH REGARD TO END-OF-LIFE DECISION MAKING}

${ }^{1} \mathrm{~T}$ Henking*, 'L Best, ' $\mathrm{E}$ Heizmann, ${ }^{2} \mathrm{~B}$ Oorschot van, ${ }^{1} \mathrm{~S}$ Neuderth. 'University for Applied Sciences Würzburg-Schweinfurt, Würzburg, Germany; ${ }^{2}$ University Hospital Würzburg, Würzburg, Germany

\subsection{6/spcare-2019-ACPICONGRESSABS. 118}

Background In Germany ACP has only gained importance in recent years. It is still a long way to a nationwide implementation. A legislative initiative from 2015 focusses the 